\title{
A review of state-of-the-art in torque generation and control of floating vertical-axis wind turbines
}

\author{
Paulsen, Uwe S.; Andersen, Elin; Griffith, D. Todd; Madsen, Helge Aa
}

Published in:

Proceedings of Technologies and Materials for Renewable Energy, Environment and Sustainability

Link to article, DOI:

$10.1063 / 1.5117052$

Publication date:

2019

Document Version

Publisher's PDF, also known as Version of record

Link back to DTU Orbit

Citation (APA):

Paulsen, U. S., Andersen, E., Griffith, D. T., \& Madsen, H. A. (2019). A review of state-of-the-art in torque generation and control of floating vertical-axis wind turbines. In Proceedings of Technologies and Materials for Renewable Energy, Environment and Sustainability (1 ed., Vol. 2123). [030021] American Institute of Physics. AIP Conference Proceedings Vol. 2123 No. 1 https://doi.org/10.1063/1.5117052

\section{General rights}

Copyright and moral rights for the publications made accessible in the public portal are retained by the authors and/or other copyright owners and it is a condition of accessing publications that users recognise and abide by the legal requirements associated with these rights.

- Users may download and print one copy of any publication from the public portal for the purpose of private study or research.

- You may not further distribute the material or use it for any profit-making activity or commercial gain

- You may freely distribute the URL identifying the publication in the public portal 


\section{A review of state-of-the-art in torque generation and control of floating vertical- axis wind turbines}

Cite as: AIP Conference Proceedings 2123, 030021 (2019); https://doi.org/10.1063/1.5117052

Published Online: 17 July 2019

Uwe S. Paulsen, Elin Andersen, D. Todd Griffith, and Helge Aa. Madsen

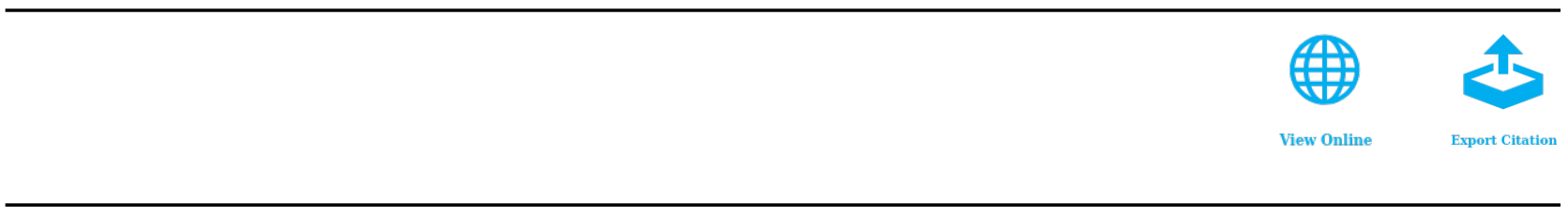

\section{Conference Proceedings}

Get $30 \%$ off all print proceedings!

\section{Enter Promotion Code PDF-30 at checkout}

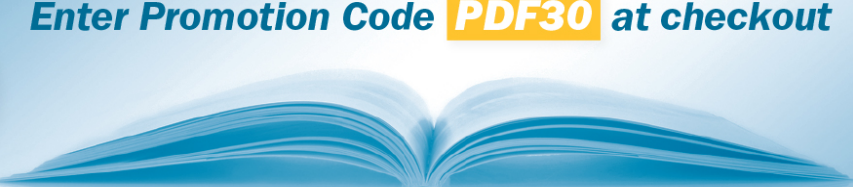




\title{
A Review of State-of-the-Art in Torque Generation and Control of Floating Vertical-Axis Wind Turbines
}

\author{
Uwe S. Paulsen ${ }^{1, \text { a) }}$, Elin Andersen ${ }^{2}$, D. Todd Griffith ${ }^{3,4}$, Helge Aa. Madsen ${ }^{1}$ \\ ${ }^{1}$ Department of Wind Energy, Technical University of Denmark, Frederiksborgvej 399 Dk-4000 Roskilde Denmark \\ ${ }^{2}$ Department of Mechanical and Structural Engineering and Materials Science, UiS, 4036, Norway \\ ${ }^{3}$ (formerly)Wind Energy Technology Department, Sandia National Laboratories, Albuquerque, NM 87185, USA \\ ${ }^{4}$ (currently)Department of Mechanical Engineering, University of Texas at Dallas, Texas, TX 75080, USA \\ a) Corresponding author: uwpa@dtu.dk
}

\begin{abstract}
Large-scale floating vertical axis wind turbines have great potential for offshore applications. This paper will review the recent developments for generating torque and controlling vertical-axis wind turbines (VAWTs) specifically for floating applications. The phenomena presented include dynamic stall and pitching of the blades, as well as design of airfoils for VAWT applications.
\end{abstract}

Keywords: wind energy, floating offshore, torque controls, aerodynamics, vertical-axis wind turbines, rotor configurations, flutter, standstill vibrations

\section{INTRODUCTION}

The increasing demand for renewable energy has resulted in new wind turbine systems, greater installed capacity, new designs and new levels of maturity over the last three decades [78]. Wind turbine systems offer increasing reliability in technical aspects, such as lifetime and operating availability. They provide electricity from wind at a competitive cost compared to other existing methods of energy supply. The areas available to wind farms are getting constricted, and the way the society use wind energy is changing. As a result of this, new markets have opened. One such market is offshore wind, where new and different concepts must be considered. The vertical-axis wind turbine (VAWT) can be beneficial for floating offshore concepts, as floating VAWTs have inherent advantages when compared to floating horizontal-axis wind turbines (HAWTs). Recently, major efforts have been undertaken in both Europe and the United States to explore this technology. The recent study made on the offshore DeepWind VAWT concept, a floating largescale Troposkien-shaped Darrieus turbine, see Figure (Fig.) 1, used the technology for VAWTs developed by Sandia between 1970 and 1995 [4]. In the DeepWind project ${ }^{1}$ [57] the previous research was applied to a floating wind turbine. A report from Sandia reviews the development and configurations of VAWTs, and the lessons learned [70]. The DeepWind VAWT concept is challenging existing offshore wind technology, and has drawn attention due to its new design, well suited for offshore conditions [58]. This project ${ }^{1}$ challenged on the assumption that stall- and variable speed control of a Troposkien shaped Darrieus rotor will be more cost competitive than a pitch controlled H-type Darrieus rotor. In the USA, Sandia National Laboratories has renewed R\&D efforts in VAWTs, investigating innovative VAWT rotor technologies at large-scale, along with efforts to pursue optimal configurations for floating wind turbines (See Fig. 2a). Several different rotor types [64] and floating system configurations [25] have been evaluated for a floating VAWT system [29,30]. Meanwhile, research on VAWTs is conducted on a global scale at universities, and some issues do not have a definite answer. It is currently unclear if the VAWT can be more economical than existing HAWT for floating offshore applications, and there is no academic agreement on how to derive the most energy from a VAWT on commercial scale with a competitive cost of energy (COE). The demonstration project INFLOW [38] combines in a similar way as DeepWind several technologies, in a configuration

\footnotetext{
${ }^{1}$ See for concept details and results www.DeepWind.eu
} 
of two counter-rotating, pitch controlled H-rotors without guy-wire support (See Fig. 2b). [23] describes in a comparative study a HAWT and two VAWT rotors (Darrieus and H-type), on structural dynamics, control systems, maintenance, manufacturing and electrical equipment. In recent reviews, [3] summarizes latest research conducted at Uppsala University on a $200 \mathrm{~kW}$ and a $12 \mathrm{~kW}$ land based VAWT, with H-rotor similar to INFLOW concept [3].

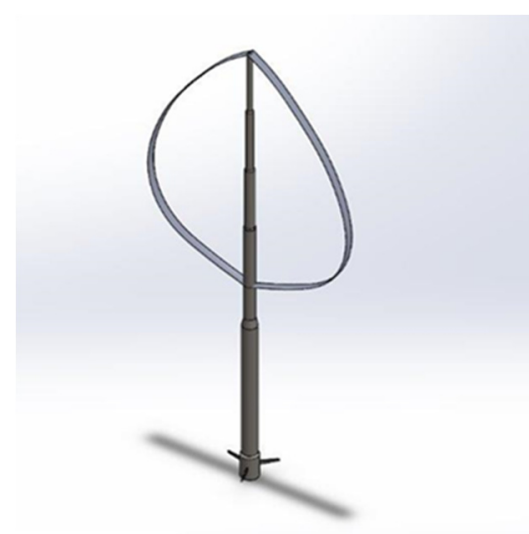

(a)

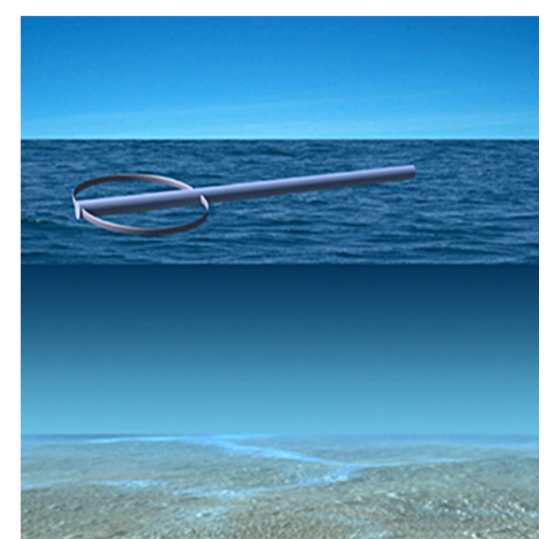

(b)

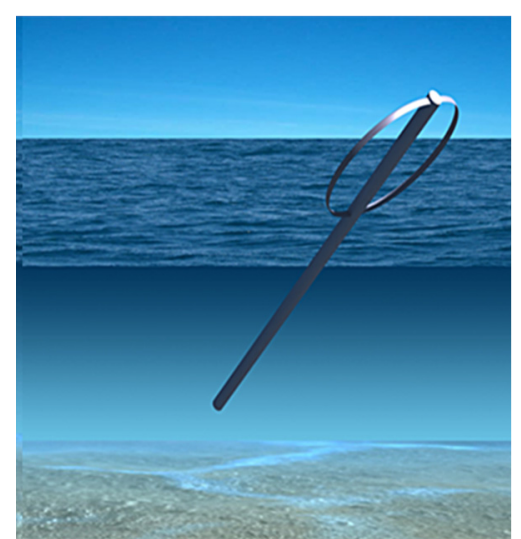

(c)

FIGURE 1 (a): 5MW DeepWind conceptual design. (b): DeepWind towing scene. (c): DeepWind installation scene [20]

This article reviews and summarizes the development trends in VAWT design and control for floating offshore applications, different designs based on ingenuity and simplicity, energy effectivity, controls mechanisms and influences on COE. The complexity of the control mechanism has an influence on the COE. Both building cost, which is a part of the capital expenditure, CAPEX, and operation and maintenance cost, called OPEX, will increase as more moving parts are added. The aim is to describe advantages and disadvantages of the various methods of control for VAWTs, with a focus on performance and energy production.

Limited information exists in literature on full-scale VAWTs measurements, in this article we deal mainly with many observations from numerical studies, from laboratory testing - and from small-scale experiments ${ }^{2}$. We also realize that this survey comprehends a limited amount of references from literature on the topic of VAWTs; vast amounts of information exist on research and developments on airplanes, from the marine sector, from the Oil \& Gas industry, and information about HAWTs developed over the years. Omitted here are details that have been achieved in aerodynamics, in aeroelasticity and efforts translating these results into the field of wind energy. An example of service to readers provided by wileyonline.com updates a survey on wind energy literature on a regularly basis. We give in this paper a selection of the many details in the extensive field, and cover some essential points with focus towards aerodynamics and its control, and the structural implications.

On controls, [3] reports an Uppsala H-rotor with PMG generator and electronics converter. [49] describes the control algorithm for the DeepWind $5 \mathrm{MW}$ conceptual design, and [62] summarizes the electrical aspects on generator and bearings with the overall simplicity outlined in [58], and in [63] on the power electronics converter.

On review of offshore floating wind energy, [34] elaborates on the potentials of using HAWTs with floating support structures, hereby explaining on the principles, challenges and interactions with controls advocating for careful design of HAWT pitching mechanism. Therefore, the reference addresses some common challenges for VAWTs.

\footnotetext{
${ }^{2}$ A offshore measurement campaign was planned in INFLOW for 2017, but cancelled due to termination of the project
} 

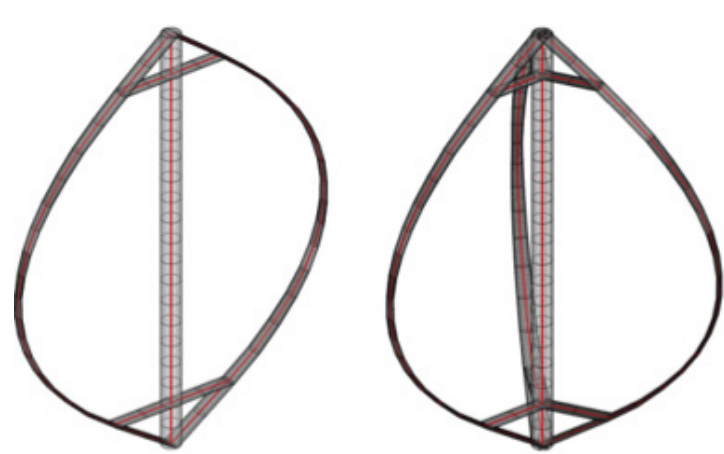

(a)

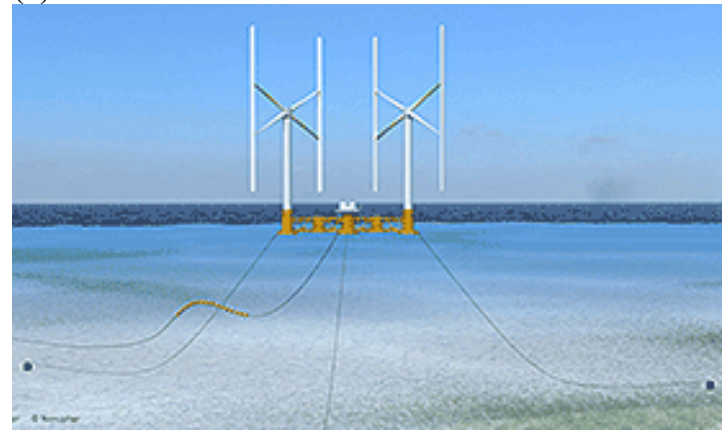

(b)
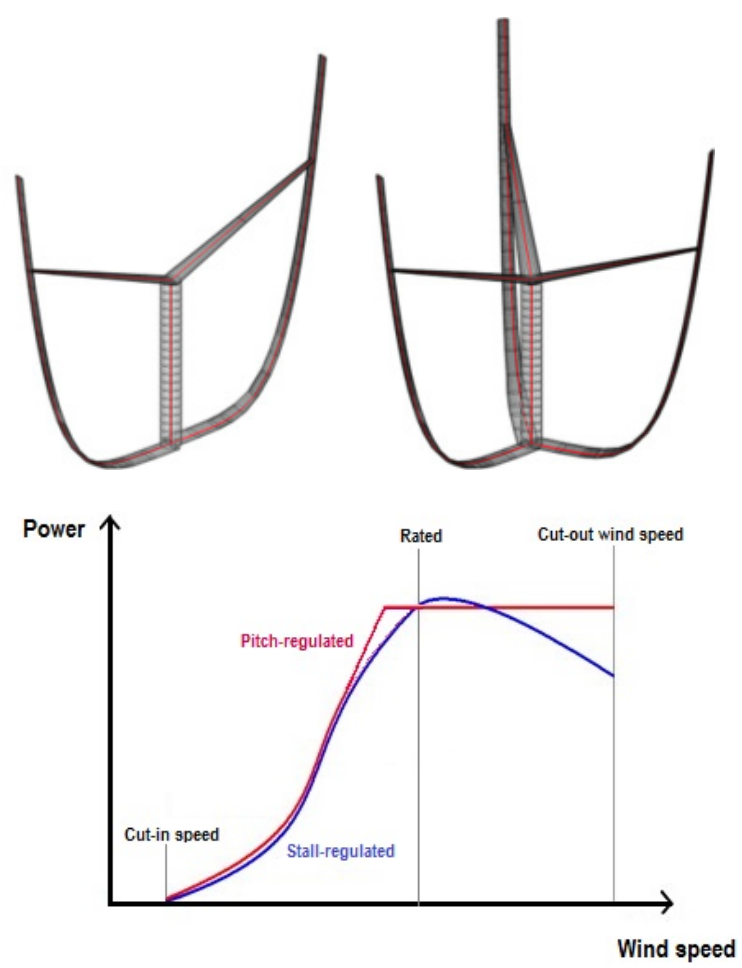

(c)

FIGURE 2 (a): Different innovative rotor configurations considered in Sandia's VAWT research [64].(b): INFLOW concept: twin rotor on tri-floater [38].(c): Power curves for pitch and stall regulated wind turbines

\section{APPROACHES AND METHODS}

This paper will look into pitch-regulated and stall-regulated vertical axis wind turbines. Pitch-regulated wind turbines have increasing power up to the rated wind speed, and then produce constant power up to a cut-out wind speed. This is achieved by pitching the blades along the longitudinal axis. At the cut out speed, the pitch control is usually no longer able to limit the rotational speed, unless pitching increases the rotor drag. At these high wind speeds, the structural integrity of the turbine can also be threatened by vibration, turbulence or gusts.

The blades and in particular the airfoils of a stall-regulated wind turbine are designed for constant tip speed ratio $\lambda=\omega \mathrm{R} / \mathrm{U}_{0}$ in such a way that the rotational speed $\omega$ decreases for wind speeds $\mathrm{U}_{0}$ above a certain value, where power is limited onwards. The control is by far non-trivial to make the design protect the wind turbine from over speeding. A reduced rotational speed leads to a decrease in power production. As the angle of attack continues to increase above a limit, stalling occurs, and the area of the blades that stalls propagates towards larger parts of the blade.

The main difference between pitch-regulated and stall-regulated wind turbines is at high wind speeds, where the pitch turbines can have a constant power production, while the stall-regulated turbines decrease power in dependency on rotational speed (See Fig. 2c). It is obvious, that curved blades are impracticable for using technically existing pitching devices. Both pitch-regulated and stall-regulated turbines have devices (e.g. spoiler, water brake, see [57]), that can keep the turbine still or in safe motion at very high wind speeds, above cut-out speed. Five different aspects of control of VAWTs will be assessed in this review: airfoil design, the dynamic stall phenomenon, active \& passive pitching of the blades, and braking/parking strategies for VAWTs.

A VAWT has three main phases of operation: starting up and operation below and above rated wind speed, and the aspects of control is evaluated in each of these three phases. [15] gives a survey of the VAWTs in comparison with HAWTs in key topics such as technology, conversion efficiency, upscaling, fatigue, and machinery position. [80] gives a dynamic model of a 2-bladed 5 MW Darrieus type turbine integrated with the OC4 DeepCwind semisubmersible support structure in a model-to-model comparison. The $2 p$ response and first natural pitch motion from wind can be observed when the wind is combined with wave. [19] makes a review on trends and technologies in floating vertical axis wind turbines (FVAWTs) and summarizes the use of conceptual platforms on stability for a tension leg platform (TLP), a semi-submersible and spar buoy with different rotor configurations, such as 5 MW 
Darrieus rotor. Resonance of floating VAWTs has been studied recently [54] where the impact of the floating support structure on modes of vibration was analyzed and compared with land-based and shallow-water monopole supports. Comparative studies on different FVAWT concepts have been conducted recently in [16] and [58]. [17] summarizes guidelines for the VertiWind VAWT project, being a predecessor of a design for the Industrialization Setup of a Floating Offshore Wind Turbine [38].

On the operation of a Darrieus rotor in an oblique flow, [65] find with a vorticity formulation an increase in power output as the oncoming wind becomes increasingly oblique comparted to that developed at normal flow conditions. The height over radius, tip speed ratio and the wake interaction are main contributors for this finding. In comparison to the tilted operation on the DeepWind demonstrator conducted in a wind tunnel, the study showed differences on the rotor efficiency [10], as seen in Fig. 9c in comparison with measurement on the Sandia Ø2m rotor with NACA0012 airfoils.

\section{New Airfoils for VAWTs}

The airfoil design can greatly enhance the properties of a VAWT, both related to increased power production and the self-starting ability. [61,36] show, that these properties are highly linked to airfoil thickness and the camber and reflex property. The airfoil pressure efficiency $\mathrm{CP}$ is highly dependent on these parameters for favorable combinations of local pressure increase/decrease along the flow direction. Most research in VAWTs is conducted on rotors using NACA airfoils, modified NACA airfoils such as SNL1850, SNLA2150 or Somers new airfoil, S824 [70].

TUDelft developed tailored airfoils for DeepWind (DU12W262), chambered with reflex properties of the trailing edge that gives a steeper $\mathrm{C}_{\mathrm{L}}$ curve than a similar NACA airfoil. TU Delft has also done research on thick airfoils [DUyyWxxx], where airfoil design methodology is explained [76]. The DU96 profile was originally intended as an airfoil section with position close to the tip of HAWTs. The performance of the designed airfoil has been tested for a range of Reynolds numbers in the order of 0.7 to 1 million, relevant for small to medium sized wind-energy applications.

[13] performs a study on a Darrieus rotor with asymmetric blades using the NACA 2415 airfoil. The analysis concluded that a cambered airfoil can have enhanced start-up capabilities, but that there are losses due to lower performance at higher tip speed ratios. The same authors then showed that a modified NACA0018 airfoil with a hinged tail would have better self-starting performance than the NACA2415 [14]. [71] show that directed guide vanes can be an advantage in straight bladed Darrieus VAWTs, then [72] conducts an experimental study of the effect of guide vanes. This study shows that the power coefficient and the torque coefficient are independent of the number of guide vanes. Cambered airfoils can make the turbine self-starting and increase the power production below rated.

Several airfoil designs for VAWTs have been evaluated over the past decades, and technology developed for aircrafts could serve as inspiration for transfer of technology into VAWTs. Classic design guide lines for the NACAairfoils $^{3}$ can be found in [35], [61], NACA bulletins (e.g. TN3007 [40]), and modern textbooks. Sandia-airfoils, cambered airfoils from TU Delft: DUyyWxxx, the RIS $\emptyset^{4}$, FFA, NREL and various symmetrical airfoils information are found in different reports from the parent organizations. Studies for achieving maximum lift for airplanes [36,40] show, that maximum lift can be considerably increased by the use of a nose flap for profiles, where the point of turbulent separation is located close behind the profile nose [45]. However, the stalling characteristics are very important to target when designing airfoils for VAWTs.

\section{Dynamic stall}

The observation of edgewise oscillations, instabilities or vibrations on modern HAWTs and later VAWTs were under extensive investigations by Sandia, see a list of references [70]. This encouraged the community to try to understand the physics behind dynamic stall, starting with studies on wings undergoing aircraft flutter (controlled aerodynamic instability phenomenon) treated for damped or divergent motion in [74] for oscillating or heaving wing sections. Theodorsen set up a 2-DOF system in non-stationary potential flow, with vortex flow acting at the trailing edge under Kutta condition at low angle of attacks. The results were pressure forces on the suction and pressure side of the airfoil, inducing small oscillatory excursions about a position of equilibrium. The classical flutter is applicable to $2 \mathrm{D}$ airfoil conditions, with lift coefficient $\mathrm{CL}=2 \pi \alpha$ providing a response $2 \pi \alpha \mathrm{F}(\mathrm{k})$, where $\mathrm{F}$ is a complex function

\footnotetext{
${ }^{3}$ NACA-airfoils were used in wing design of airplanes, and they are widely used as airfoil properties reference

${ }^{4}$ Particular airfoil types have been designed for wind turbine rotors, type A,B,C,P type, see[7, 8, 9]
} 
and $\mathrm{k}$ is the reduced frequency. This linear theory is only valid for non-stalled conditions for VAWTs. Explanation of self-oscillatory motions by using the example of the Tahoma Narrows bridge disaster in 1940 [81] eradicates misconceptions between the aerodynamically induced condition of self-excitation in a torsional degree of freedom and the «elementary forced resonance of a mechanical oscillator». The disaster has served as motivation for studying vortex separation on bluff, square and rectangular cross-sections. [32, 31] studied the physical phenomena related to stall-induced vibrations. [68] studied this for HAWT blades at standstill, and this reference should be applicable on VAWTs with high angles of attack during normal operation [69]. Improved sub-models for the wind turbine blade vibration problem are described here. These are usually called dynamic stall models. The paper also includes the model from [47]. Every airfoil has a point where the pressure generated by the circulation around the airfoil causes the flow to detach. At this point, the increase in lift force halts, and the drag forces increase. But the transition from one state to the other cannot be instantaneous, and trailing edge stall emerges. A sub-model for trailing edge stall for HAWTs is incorporated adequately by [47]. An unpublished report [59] investigates the applicability of this model for VAWTs, and recommends a modification of the instantaneous lift coefficient due to the circular motion of VAWT blades. In the case of normal operating HAWTs, [6] studied the particular double stall phenomena. These phenomena were observed during power performance measurements on HAWTs as far back the mid-80's. The double stall has a massive, undesirable effect on the determination of maximum loads, due to an observed instant shift from one load level to another. [1,5] combines information of literature survey, wind tunnel study, and CFD simulations to determine the origin and effect of leading edge stall, specifically on NACA $63-2 \mathrm{nn}$ and RISØ airfoils ${ }^{4}$. The wind tunnel study on a NACA 63-2nn blade showed clear distinct levels of stall on a non-tapered airfoil, very similar to stalling patterns known from airplanes [36]. High drag level occurred when low lift was observed and low drag level emerged when high lift was present. From experiments, [1] concludes that zigzag tape of various roughness applied on the leading edge eradicates double stall on NACA 63-215. Another conclusion is that double stall on airplane airfoils appears as leading-edge stall, trailing-edge stall or a combination depending on the thickness of the airfoils. Important parameters affecting maximum lift are Reynolds number (Re), airfoil shape and turbulence. Computational fluids dynamics (CFD) investigation on NACA 63-215 and RISØ airfoil ${ }^{4}$ for fully turbulent and transitional flow were made, and computational results from transitional flow agrees well with measurements of leading edge stall. [1] further stated from known literature: i) a highly cambered or thicker airfoil section does not present difficulties to the flow around well rounded leading edge, and ii) CFD results supports this conclusion. Furthermore, iii) double stall is closely related to the actual geometry of the leading edge of the airfoil. An airfoil iv) subjected to a change of surface roughness from rain or bugs can avoid double stall, and that $\mathrm{v}$ ) double stall probably can be avoided with new airfoils design.

An experimental wind tunnel facility situated at TUDelft was used to measure dynamic stall with the particle image velocimetry (PIV) method on a rotating $\varnothing 0.5 \mathrm{~m} \mathrm{H}$-rotor[18]. This can be used experimentally to benchmark rotors in dynamic stall conditions around $\lambda \sim 4.5$. The small rotor size leads however to an expected discrepancy due to the Re effects, in the order of $10^{2}-10^{3}$ in comparison with a MW full-scale rotor. In absence of full-scale experiments, previous works on VAWTs [51, 22] deal with applying computational methods for predicting dynamic stall (elaboration of principal stages of leading edge originating dynamic stall, $\lambda<4$ ) and often comparing with available references, in particular with experimental results obtained by Sandia [70]. A PIV study conducted in a water tunnel on dynamic stall of a NACA0018 airfoil, undergoing various unsteady motions at $\mathrm{k} \sim 0.12$, showed flow behavior associated with the driving pitch/surge frequency for leading edge vertical structure[21]. A secondary separation mode, twice the pitch/surge frequency, shows for nose down pitching an anti-spinning vortex system reattaching effect. The results, obtained at Re of about $10^{5}$, share prior to stall similarities observed in similar experiments carried out at TUDelft [67]. Full-scale VAWT flow effects incorporate Coriolis terms, in comparison laboratory experiments are conducted with pitching/surging blade in a uniform onset. However, Coriolis effects on the boundary layer and double stall during these laboratory tests using NACA airfoils seems not to be observed. Literature on other tests for studying double stall on VAWTs at high Re is not known to the authors.

The above information applies as general cases to the conditions of a blade or airfoil pitching around a central axis. Darrieus turbines with fixed blades are characterized by low, or even negative torque, at tip speed ratios $\lambda$ below that at which they are designed to run $[\lambda<\sim 3]$. This means that they have a difficulty self-starting and need grid supply that can drive the turbines to speed when enough wind is measured. In turbulent wind, this low torque inhibits their energy capture. Particular airfoil chamber and reflex design offers ways to enhance self-starting, because of their high influence on maximum lift and stall capability. One control method described in this paper is the passive control by dynamic stall. A VAWT has an inherent unsteady aerodynamic behavior due to the variation in angle of attack with the angle of rotation, and the experienced velocity and Re. Therefore, dynamic stall is an intrinsic part of the operation of a VAWT at low tip speed ratios, and it has a significant impact on both loads and power [52]. The dynamic stall phenomenon can both inhibit self-starting and keep the turbine from over-speeding at wind speeds above rated. The 
peak power attains at wind speeds of narrow range, though the turbine drive train and generator must be sized to accept the maximum power output in a safe way. Therefore, a reduction of the rated wind speed compared to a turbine operating without upper power limit is economically favorable [ the reduction will influence the set point of the lower cut-out wind speed]. Since the wind is infrequent in the range above the regulation wind speed, the net loss of produced power is relatively small. It therefore allows the use of smaller, less costly equipment [52]. Additionally this feature enhances safety issues concerned with start-up at high wind speed.

Development in modern HAWTs has shown it is possible to modify stall properties using stall strips [75]. Stall strips are triangular shaped devices attached to the leading edge of an airfoil. The purpose of the strips is to initiate flow separation. HAWT rotor developments have also shown that vortex generators (VG) are an effective way to impact the stall properties of an airfoil. A VG is a small vane attached to the lifting side of the turbine blade, usually in the height order of the boundary layer. The effect of VG is to delay dynamic stalling, and local flow separation. VGs generate vortices that energize the boundary layer making it more resistant to separation and subsequent stalling.

\section{Pitching blades}

Straight-bladed H-rotors have two more options for control: the active and passive pitching of the blades. By pitching the blades in a cyclic (and blade independent) way, it is possible to increase the time that an airfoil produces lift. This gives an overall increase in power production below rated wind speed but at the expense of the turbine being independent on wind direction. Pitching can also be used to control the power output at rated wind speed, and avoid over-speeding when the wind is gusty. When the turbine experiences wind speeds above rated power, blades can pitch so that there is less lift and more drag. This effect is due to increasing flow separation along the blade length (blades are pitched into stall). In a reverse controlled process, loads and power can be reduced by pitching towards lesser angle of attack, which is a feasible way to do alleviation. In the report of [79] they evaluate the potential of a circulation controlled vertical axis wind turbine with straight blades for being able to facilitate boundary layer control (by blowing) and cyclic pitching of the blades hereby increasing the efficiency of the rotor. A number of researchers have demonstrated that the provision of variable-pitch blades will make the Darrieus turbines self-starting. For instance, it

has been shown that if the blade pitch angle is varied as a sinusoidal function of the azimuth angle, in phase with the variation of the angle of attack, the amplitude of the angle of attack variation experienced by the blade can be reduced [56].

\section{Active pitch of a H-rotor with straight blades}

The active pitch designs may be defined as those systems that produce blade pitch change through means other than the direct action of the aerodynamic forces acting on them [56]. This can be achieved by systems that measure and calculate proper pitch angles continuously, and uses actuator systems to drive the blades to the desired angle. VAWTs can also have blades that are driven by a central cam. In [28] this method was tested with four different amplitudes of pitch variation. The results show that large amplitude gives a good starting torque and good performance at low $\lambda$, but the turbine is unable to reach higher $\lambda$ and high efficiency. Small amplitude showed to give good performance in high $\lambda$ but resulted in poor starting capabilities. This indicates the need to have a variable pitch scheme where the amplitude is variable. This is difficult to achieve with the cam-design. Another requirement would be a measurement and control system to register the wind speed relative to rotor speed at different wind direction. Another possibility is to use circulation control and particularly design it for best combination of load reduction and power utilization over a revolution, making it possible to meet e.g. the above stated requirement. Practical circulation control application, as well as its complexity is explained recently in [24]. In [55] the optimal variation of angle of the blades for a two-bladed H-Darrieus wind turbine using a genetic algorithm is determined. The $7 \mathrm{~kW}$ turbine had constant chord blades with a NACA 0015 airfoil. Analytical functions were considered for describing the azimuthal variation of the blades' pitch angle; a sinusoidal one and a more general one. When the pitch is optimized towards the lower wind speeds, it returns a gain of almost $30 \%$ in annual energy production with a polynomial optimal pitch control. 


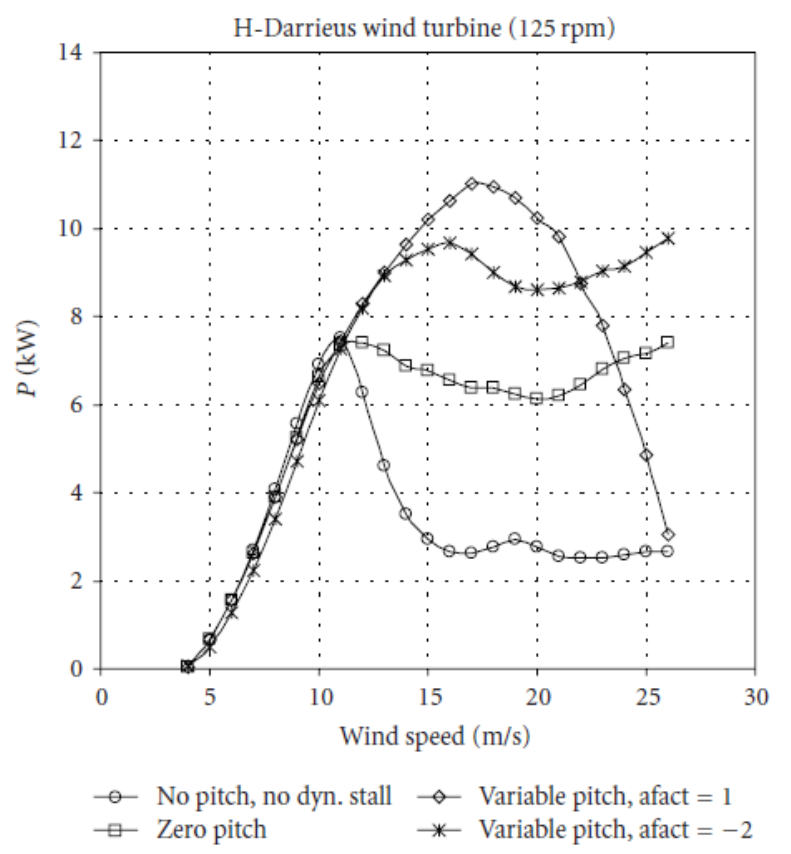

(a)

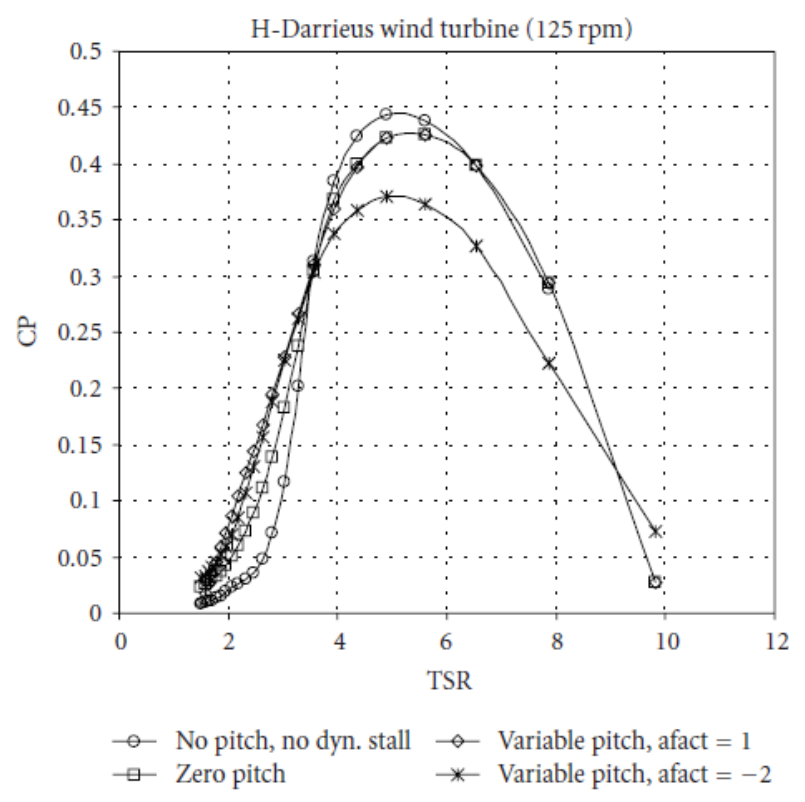

(b)

FIGURE 3 (a): Power versus wind speed for the $7 \mathrm{~kW}$ VAWT with fixed and variable pitch blades. (b): Power coefficient versus TSR for the $7 \mathrm{~kW}$ VAWT with fixed and variable pitch blades. afact $=1$ is simple sinusoidal variation of pitch, afact $=-2$ is a general expression that relates blade pitch to local flow conditions. [ 55]

The paper regards the "variable pitch" as a viable solution to the alleviation of the negative effects of dynamic stall, which is efficiency loss and vibrations, as well as an improvement in the rotors self-starting capabilities and torque ripple smoothing $[42,56]$. The $30 \%$ increase in annual production might justify the supplementary costs related to the implementation of the variable pitch system, see Fig. 4 [55]. The amplitude of sinusoidal blade pitching motion should vary with the wind speed and TSR to maximize the power output [39]. For $\lambda<0.5$, high amplitudes [ 35 $]$ works better, while for $\lambda$ more than 2.0 , the pitch amplitude should be reduced to around $10^{\circ}$.

\section{Passive variable-pitch of a H-rotor with straight blades}

The problem of achieving a decreasing pitching of the blades with increasing $\lambda$, as well as the need for a measurement and control system is the main arguments for a passive variable-pitch system. Here, pitching is determined directly by the wind forces acting on the blade. The blade is free to pitch along a spanwise, longitudinal, axis near the leading edge. The aim is to point into the apparent wind. [12] and [42] shows that two different passive variable-pitch VAWTs can achieve self-starting using what is called an inertial type of pitch control. The design by Kirke and Lazauskas has a threshold that must be exceeded by the aerodynamic moment on the blade before any pitching will occur [42]. This prevents small oscillations, and lets the turbine operate as a standard fixed-blade Darrieus turbine at high $\lambda$. However, an impact each time the blade passes zero pitch position must be handled. Kirke built and tested a turbine of $6 \mathrm{~m}$ diameter, and even though some discrepancies were found between measured and predicted results, it proved to achieve self-starting and gave more credibility to the inertial type pitch control.

Thus the main component of torque ripple, when the blades remain largely un-stalled, occurs at a frequency of twice the rotational frequency, and its half-amplitude is roughly $100 \%$ of the mean torque [73].

Pitching will provide a more even load scheme over the cycle, by lowering the load in the first part, then increasing it in the last part.

\section{Loading}

The choice between straight or curved blades is probably mainly determined by structural considerations reflecting that centrifugal loading of straight blades are more costly than using lesser aerodynamically efficient blade airfoil sections. As shown in various references for VAWTs, see for example [70] and demonstrated particularly on the $34 \mathrm{~m}$ 
Sandia rotor [70] both pitch and non-pitched VAWTs generates cyclic loads occurring in the central column connecting the blades. For a 2-bladed turbine large cyclic drag and side-forces will occur at two cyclic peaks per rev in the tower base and contributing to fatigue of the column. A 3-bladed rotor will average the load peaks over the rotor revolution cycle more evenly compared a 2-bladed. The aerodynamic torque for a 2-bladed configuration generated is near zero when the blades are moving directly up- and down-wind, and reaches a maximum at one-quarter revolution from this position.

Aeroelastic instabilities originating from flow adding energy into the structure [negative damping effect] are sources of unwanted excessive vibrations and fatigue, as shown in [78], [27] on an onshore Deepwind concept, and in [49] on simulation results of the structural modified- compared to the original DeepWind design. In this study, edgewise instabilities observed during operation for the original design were remedied by changing structural stiffnesses in blades and tower without changing weight more than $10 \%$, and modification of the generator controls and floater length, though edgewise vibrations persisted during standstill. Classical flutter aeroelastic instability has been addressed for large-scale VAWTs in recent work at Sandia [53]. In this study, flutter margins for different rotor types including Darrieus and V-VAWT rotors were analyzed for rotors composed of both glass and carbon materials.

\section{Braking Strategies}

Mechanical and aerodynamic braking are required in wind turbines to avoid overspeed and for bringing the rotor to rest above the cut-out speed and below the cut-in speed. Mechanical braking is provided by mechanical disc brakes, or similar. In VAWTs, although mechanical brake requirements may be larger than for HAWTs, mechanical brake requirements may be reduced through stall control and generator torque, as touched upon above. Aerodynamic braking, on the other hand, can be provided by blade pitch, which is standard in HAWTs; and this approach is utilized in several VAWT designs although it is only applied in the case of straight bladed H-VAWT configurations. For the case of other VAWT rotor types, such as Darrieus rotors, aerodynamic braking, and braking in general, is more complicated. This leads to larger and/or redundant braking systems and to consideration of novel braking strategies. As an example of a novel braking strategy considered for VAWTs, in a series of prior Sandia studies a "pumped spoiling" approach was investigated wherein a large number of small holes were drilled in to the upper and lower surfaces of the VAWT blade near the equator [43]. The air volume through the carefully designed hole placements was controlled to achieve rotor load reductions, which was demonstrated for the Sandia 5m VAWT.

\section{RESULTS}

\section{Airfoils for VAWTs}

Sandia has developed a tailored airfoil SNLA1850 for their VAWTs and by FloWind Corp. on SNLA2150 and $\mathrm{S} 824^{5}$ for better performance of the FloWind $\varnothing 19 \mathrm{~m}$ rotor. These airfoils have a sharp leading edge, which makes them suitable for higher tip speed ratios. The root sections of a phi-rotor experiences higher angle of attack, so the rounded leading edge of a standard NACA airfoil performs better. The tailored airfoil exhibits more reliable turbine operation via better tip speed ratio range cut-off near the peak $C_{P}$ condition over the standard NACA 4-series, and is implemented on a 3-bladed DeepWind turbine, see below. The DeepWind project used symmetric common reference NACA Airfoils for designing the reference $5 \mathrm{MW}$ wind turbine concept, but had an intention to experiment with the camber/reflex airfoils from TU Delft. We believe that this would enhance the DeepWind rotor for higher energy production. The airfoil tailored to a specific section of a blade serves two purposes: Structural strength and aerodynamic performance. Different propelling forces between the root and equator section would cause localized edgewise bending on a blade of a uniform dimension from the root to the equator section. This edgewise bending is insignificant for small-scale rotor, but for large-scale rotors, it would be detrimental. Thus, in order to minimize the fatigue, airfoil chord dimension was altered, so that the propelling force would be uniform from the root to the equator. In addition, the chord of the root section was made thicker for the same purpose of reducing fatigue due to bending, and compensate for lower TSR and higher angles of attack. In the actual case, DU12W262 airfoil shape is the result of an optimization for aerodynamic and structural performance [60]. Selected from an initial population of airfoils through a genetic algorithm, the shape is evaluated via two objective functions. The optimization algorithm used was presented firstly in [67]. The structural objective function was defined as the bending stiffness in flapwise direction

\footnotetext{
${ }^{5}$ http://www.airfoils.com/index.htm, accessed 17-08-2016
} 
of the airfoil per wall-thickness, in reference to the centroid of the airfoil. The aerodynamic function is based on a determined range and distribution of angles of attack over the turbine revolution. The range of angles of attack will vary for different tip-speed ratios and different values of 3c/2R (assuming rigid, fixed pitch blades); for the present case, a single evaluation interval of angles of attack $\left(\Delta \alpha=14^{\circ}\right)$ is accounted for in a range of possible angles of attack $-20^{\circ}<\alpha<20^{\circ}$. The function is based on the angles of attack distribution described in [67]. Any variation of dynamic pressure with the azimuthal position is not taken into account, due to the relatively lower impact shown in a secondary analysis, where it was found that the dynamic pressure variations mostly average out across leeward and windward regions. The optimized airfoil generation produces geometrical shapes with a wide range of thickness, among which the one with $\mathrm{t} / \mathrm{c}=26.2 \%$ was chosen. The resulting DU12W262 airfoil shape is presented in Fig. 4 .

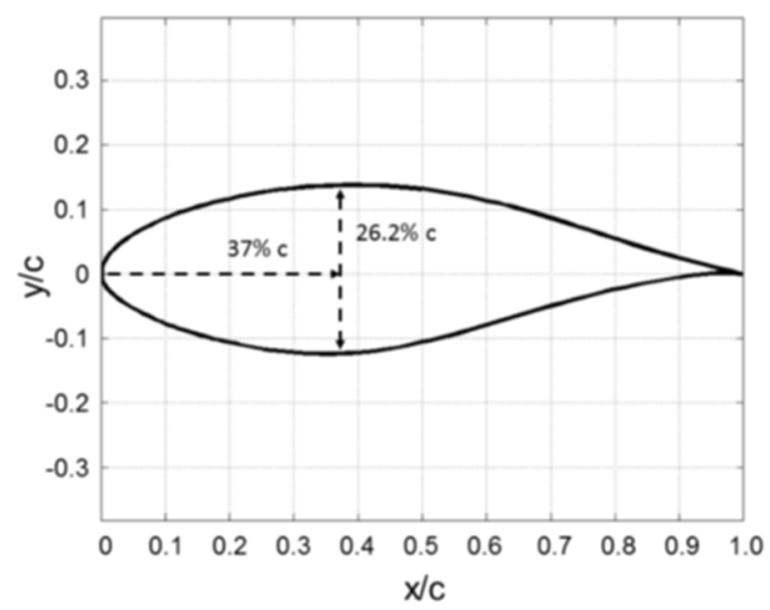

FIGURE 4 DU12W262 airfoil geometry [60]

The DU12W262 airfoil shape has been tested on a model of chord $\mathrm{c}=0.25 \mathrm{~m}$, span $\mathrm{s}=1.25 \mathrm{~m}$, aspect ratio $\mathrm{AR}=\mathrm{s} / \mathrm{c}=5$ and thickness $\mathrm{t} / \mathrm{c}=26.2 \%$. The model has been vertically installed in the closed-circuit low-turbulence wind tunnel (LTT) of the TU Delft laboratories, in an octagonal test section $1.80 \mathrm{~m}$ wide, $1.25 \mathrm{~m}$ high and $2.60 \mathrm{~m}$ long, resulting in a blockage ratio from $3.6 \%$ to $4.7 \%$ in the range from $-20^{\circ}$ to $20^{\circ}$ angles of attack. The pressure computation, see Fig. 5 for Re $1.0 \times 10^{6}$ shows the evolution of the pressure coefficient along the suction and pressure side, in comparison with data reproduced from XFOIL computations. Despite the effect of the laminar separation bubble, a good agreement is found a part from the closest region near the leading edge at $+5^{0}$ angle of attack, where the PIV underestimates the peak suction pressure. Further investigation remains to elucidate the role of the laminar bubble in the airfoil optimization procedure. It is supposed that the laminar separation bubble will allow for the wide drag bucket and thus the high lift-slope. In particular, it has been confirmed that the location of the laminar bubble does not vary significantly with angle of attack.

The variability of the airfoil performance with different Re numbers has been investigated in more detail by use of the wind-tunnel wall-pressure sensors. Fig. 6 presents the airfoil lift coefficients for different Reynolds numbers, in both free (a) and forced boundary layer transition (b) configurations as obtained from integration of the wind-tunnel wall-pressure. Fig. 6 and Fig. 7, (a) show a relatively low effect of Re in the performance of the airfoil under free transition, mainly evidenced by a slight slope variation induced in the lift curve. With decreasing Re, a shift of the curve towards negative lift is noticeable. The configuration with forced transition in Fig. 6 and 7 (b) presents a similar behavior with the change in $\mathrm{Re}$, although the effect of the fully turbulent flow in the airfoil delays stall to respectively $+15^{\circ}$ and $-20^{\circ}$ angles of attack, in comparison to $+10^{\circ},-12^{\circ}$ in the clean configuration. 


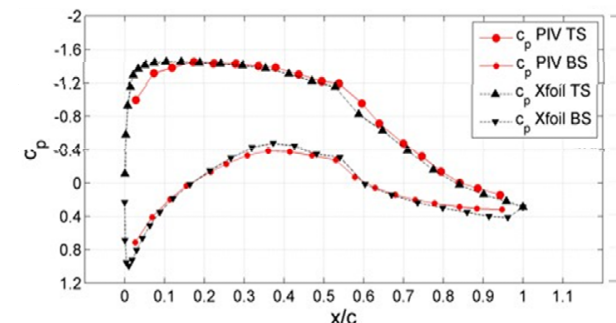

(a)

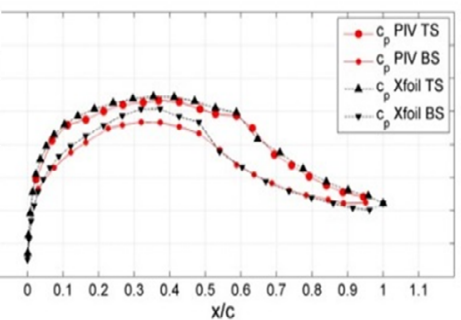

(b)

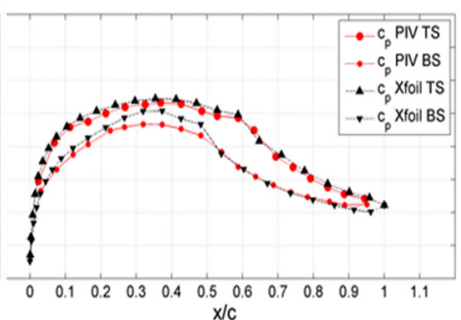

(c)

FIGURE 5 Pressure coefficient distribution for top [T] and bottom [B] airfoil surfaces [S], results from PIV integrated pressure, XFOIL. Angles of attack $-5^{\circ}(a), 0^{\circ}(b),+5^{\circ}(c), R e=1.0 \times 10^{6}[60]$

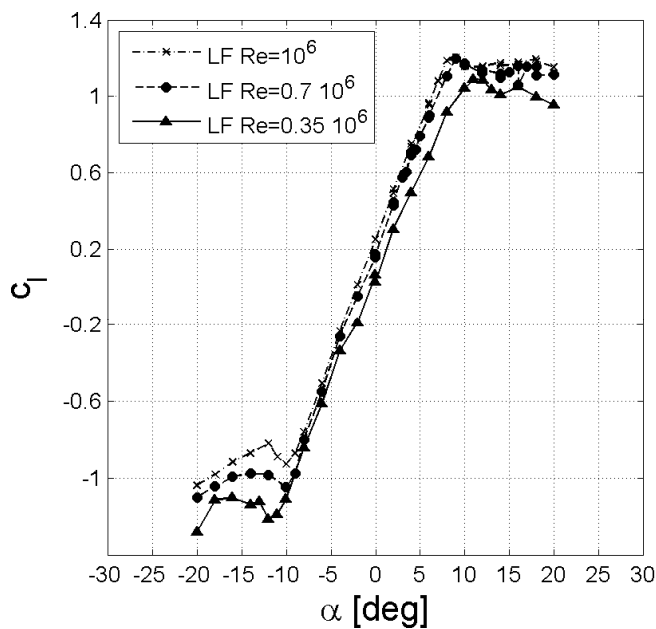

(a)

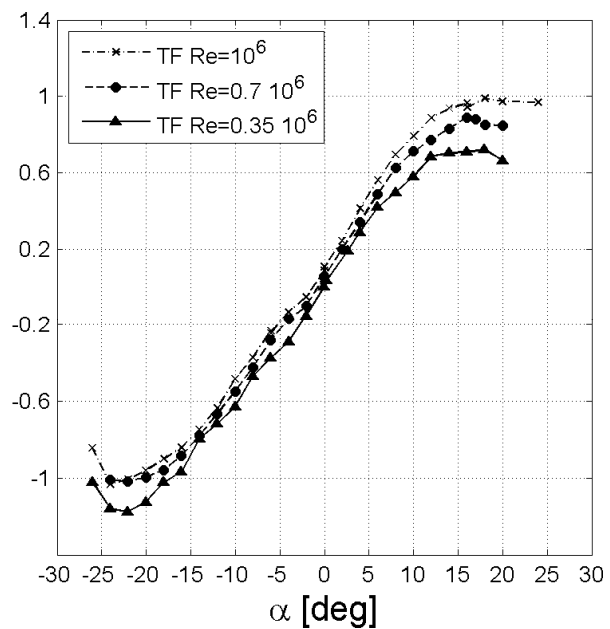

(b)

FIGURE 6 Lift coefficient (experimental) for the DU12W262 under free(a)] and forced (b) transition [60]

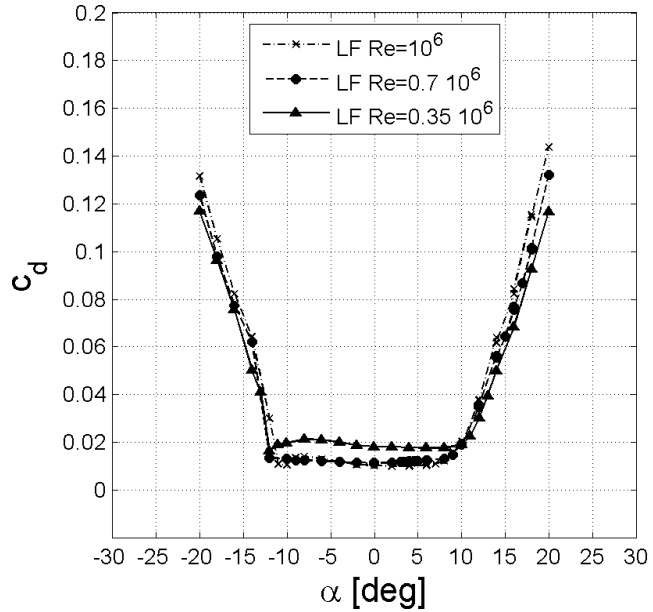

(a)

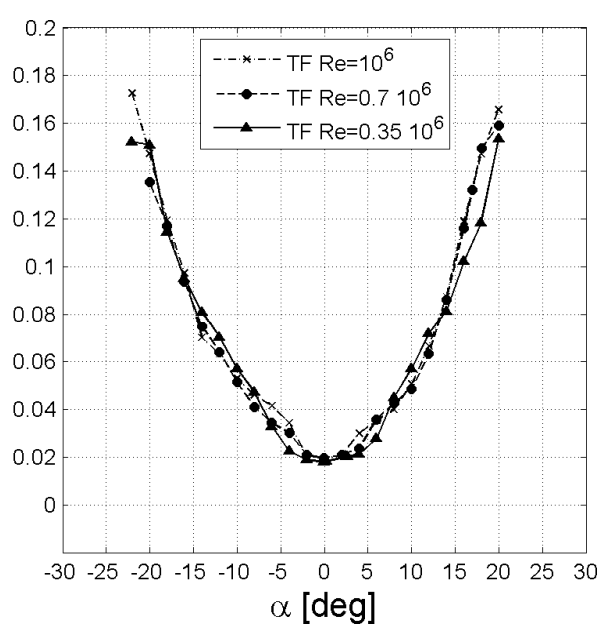

(b)

FIGURE 7 Drag coefficient (experimental) for the DU12W262 under free a) and forced (b) transition [60]

The XFOIL simulations agree for most of the range of angles with measurements [not shown here], slightly overpredicting lift for angles higher than $+10^{\circ}$. Few differences are noticeable for the two investigated Reynolds numbers, which are primarily detectable on the measured drag coefficient. Similar to the lift coefficient distribution, the drag coefficient shows typically higher values reported in the separated zones than in the XFOIL simulations, a fact ascribed to the way the boundary layer transition is obtained in the experiment with respect to the XFOIL simulations. The calculations are further carried out for the forced transition test cases and compared again to the wall-pressure probes 
and to the wake rake results. The resulting curves show a much higher over-prediction of the experimental results compared to the XFOIL simulations. The forced transition is experimentally obtained with zigzag tape of $0.4 \mathrm{~mm}$ thickness and $6 \mathrm{~mm}$ pitch and positioned at $2 \%$ chord. Although the height of the zigzag tape is within the commonly used height range [from $0.07 \mathrm{~mm}$ to $0.47 \mathrm{~mm}$ ], the relatively high value might justify the discrepancies with the XFOIL simulations, especially in the separated region. Similarly, in the XFOIL simulation, the airfoil transition is imposed at $2 \%$ chord and the results computed. The airfoil sensitivity to the presence of fully turbulent flow is relevant, especially with respect to the free-transition case. No-hysteresis phenomena are noted in any of the steady change of angles of attack.

A comparison of the performance of DU12W262 and NACA0018 is given in Fig. 8 reveals, that an improved lift increase over angle can be achieved with DU12W262, and that $C_{d}$ differentiates in comparison with NACA0018 some additional effects when comparing measured $C_{d}$ with numerical results. Fig. 9 shows that the discrepancies observed for the two airfoils have two different origins. While for the NACA0018, the source is a difference between experimental and numerical prediction of the lift slope, in the case of the DU12W262, the discrepancy is mainly due to a higher experimental drag than predicted numerically. The difference in drag for the DU12W262 is most probably a consequence of the difference between the numerically predicted transition inside a small laminar bubble for minimum drag and a different behavior in the experimental results. Although the presence of a small separation bubble and transition can be observed in the experimental results, such a phenomena is very sensitive, and can lead to smaller or larger drag values than predicted.

The simulations using the experimental and numerical airfoil polar results in Fig. 9 and Fig. 10 show that the new DU12W262 airfoil out-performs the NACA00xx series airfoils that were used in the initial population of the genetic optimization method from which the DU12W262 originated. However it is also realized, that the flow curvature effect experienced by a blade section of a VAWT primarily can be coped with operating rotors in a flow. Future experiments of a VAWT blade section in rotation could answer on the flow curvature effects, in particular on how it would suppress or support aerodynamic damping.

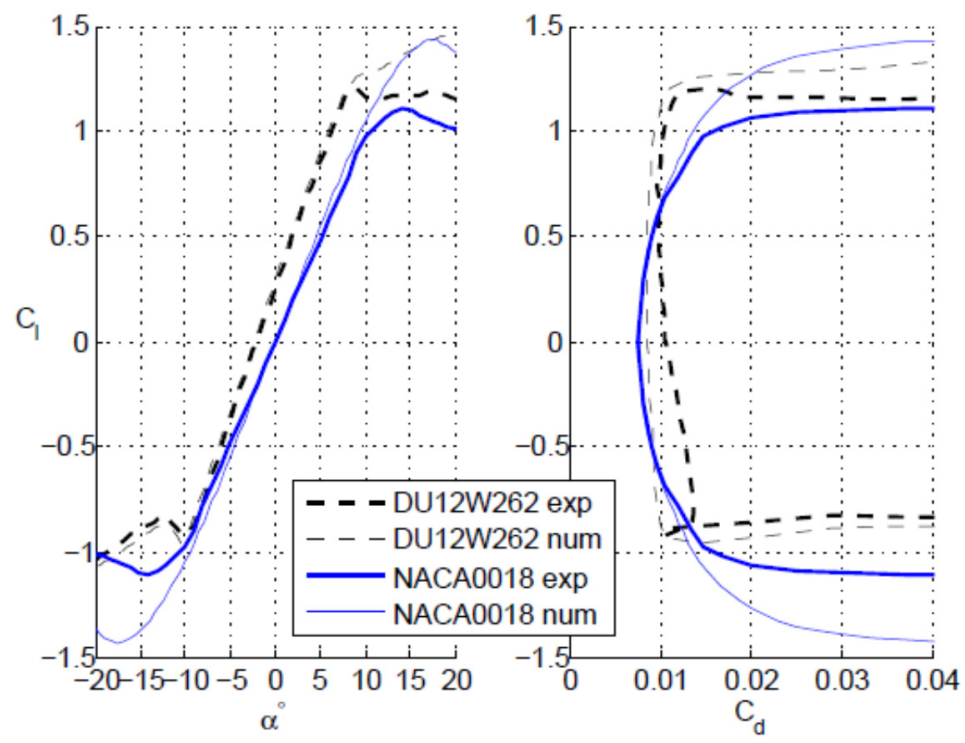

FIGURE 8 Numerical and experimental polar for the airfoils DU12W262 and NACA0018 [60]

From Fig. $9 \mathrm{c}$ a comparison of $\mathrm{C}_{\mathrm{P}}$ between the $\varnothing 2 \mathrm{~m}$ Sandia- and the DeepWind demonstrator rotor is made, showing free field and wind tunnel measurements for specific conditions, and compared with computations conducted with different airfoil databases on the Sandia rotor[11]. The difference in rotor efficiency for a simulated MW turbine (Fig. 9a, and Fig. $9 \mathrm{~b}$ with measurements indicate Re influences compared to full scale. The difference in $\mathrm{C}_{\mathrm{P}}$ (Fig. 9c) seems to originate from differences between NACA0012 and DU26W12 airfoils efficiency, rather than rpm differences. In addition, a note on the efficiency decrease of the DeepWind rotor from tilted turbine operation. 


\section{Dynamic stall}

Self-induced vibrations shown in [69] on a DU96-W180 airfoil at 90deg angle of attack revealed instability effects, and compared with the lift coefficient performed by DUW262, in particular in deep stall, the airfoil should be checked on potential occurrence of self-induced vibrations.

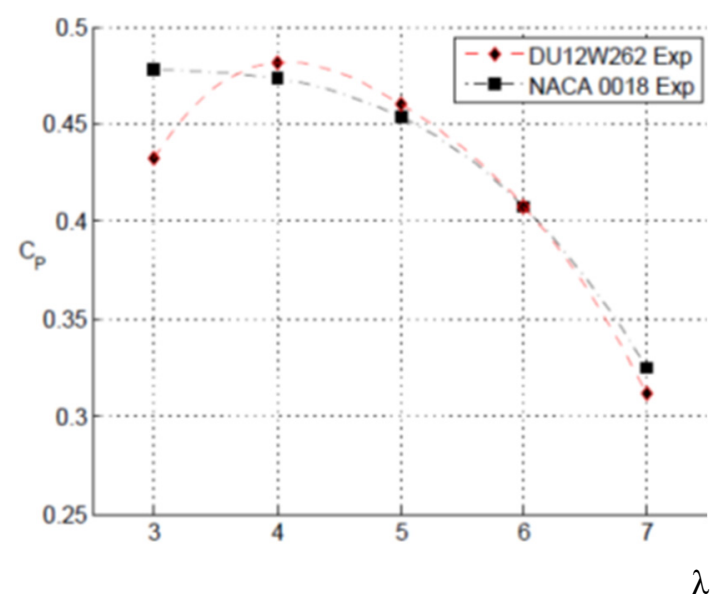

(a)

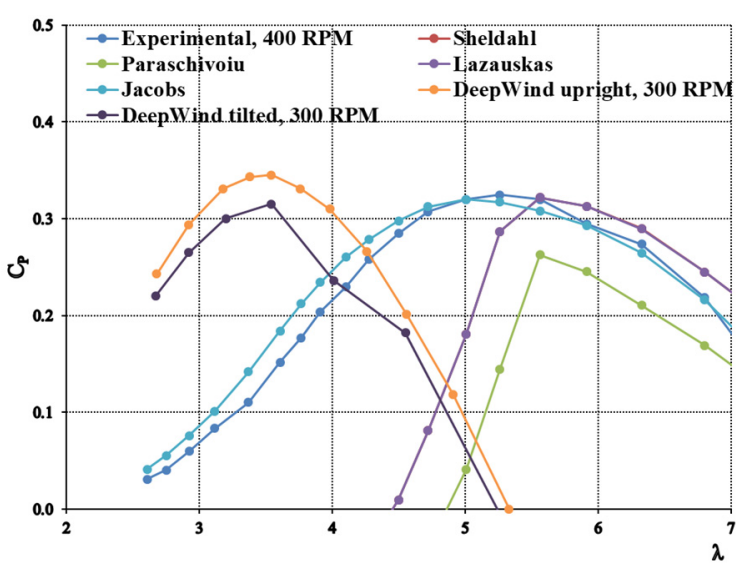

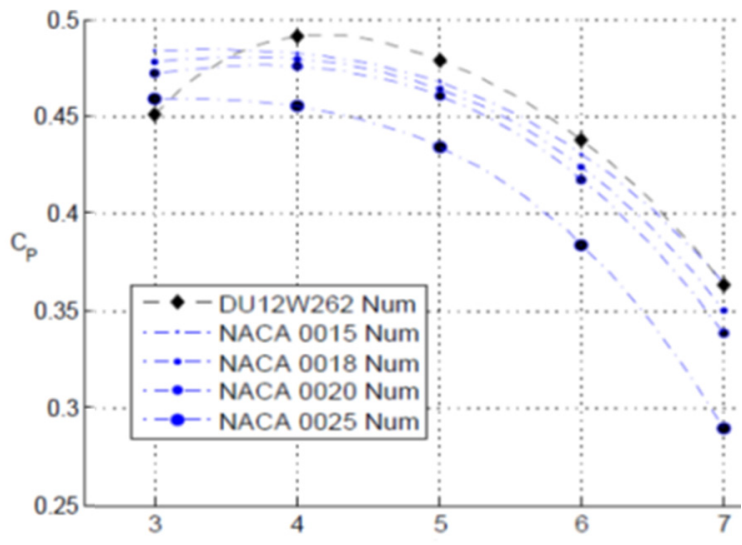

$\lambda$

(b)

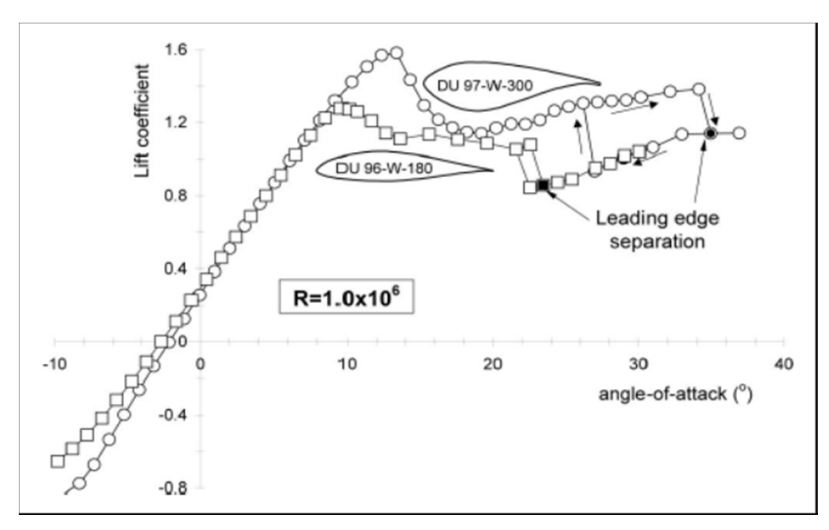

(d)

(c)

FIGURE 9 Simulated and measured power coefficient (CP) of a three bladed VAWT as a function of tip speed ratio ( $\lambda$ ). (a): for the DU12W262 and NACA0018. (b): comparison of 2D experimental data for the DU12W262, NACA0015, NACA0018, NACA0025, and NACA0030 using 2D numerical data [60]. (c): VAWT rotor performance of $\emptyset_{2 m}$ DeepWind demonstrator rotor tested in Politecnico de Milano wind tunnel [10] and compared with experimental and theoretical performance data for similar rotors [11].(d): Static lift coefficients for different airfoils, obtained in LTT wind tunnel of TUDelft [76].

\section{Pitching of blades}

[56] developed a concept with flexible elastomeric components, but concluded that a combination of lower torsional stiffness while providing enough tensile stiffness, appears to be difficult. Another challenge is that the material properties could change with time, thus affecting the sensitive response of the blades. The other concept tested by [56] produces the restoring moment from inertial loads in rolling contact with the rotor. The results were promising, but are stated to require more refinement to reduce effects of friction and parasitic drag. A comparison with the simple pendulum design of Sicard[66] and Kentfield[41] predicts performance in the same range as the rolling concept, and further study is required to see if the added control over the restoring moment is proving beneficial, or if it makes the turbine less reliable or more expensive. 


\section{Curved blades}

In a large-scale phi-rotor, gravity-induced bending stress becomes significant, since the length of a typical phirotor blade is almost three times (Deepwind 2.7[58]) a HAWT blade for a turbine with the same swept area and solidity. $[55,70]$ mention that gravity-induced stress is related to rotor height-to-diameter (H/D) ratio. Lower H/D ratio leads to greater gravitational stresses, but the type of airfoil can be tuned to minimize gravity and radial aerodynamic influences. On the optimization for limit stresses occurring in the blades, a detailed analysis of the Troposkien shape resulted in a modified Troposkien shape with blade maximum strain $5000 \times 10^{-6} \mathrm{~m} / \mathrm{m}$ [57] and with industrialized blade section junctions[58]. On the influence of struts and parasitic drag, [2] estimations of this made the relative importance of keeping parasitic drag low. Sandia also made the conclusions that for phi-rotors i) Twoblade design is more cost-effective than three blades, ii) Struts should be kept short or possible eliminated since they add parasitic drag and cost, and iii) the blade airfoil shape should be tailored [70].

\section{Straight-bladed H-rotors}

Sandia reported further that the H-rotor has a high potential for cost-effective offshore wind power generation [70]. They mention that the support bar for an H-rotor can be used as an aerodynamic braking system in strong winds. The airbrake system is a standard aerodynamic brake for commercial airplanes, which deploys extended flaps during landing. For straight-bladed small VAWTs, the gravity-induced bending stresses are of less importance, as the blades are shorter and have lower bending moment. The blades are more rigid at the same chord-length and thickness than a phi-rotor blade, positioned vertically, and supported by arms. The support arms are responsible to carry the gravityinduced bending stresses, and can be tapered from the shaft to the blade. Drag-effects and damping occurs with potential considerable amount. The recent straight-bladed H-rotors are made of glass-fibre reinforced plastics and carbon fiber reinforced-composites, which can sustain continuous cycles of edgewise and flapwise bending stress during the blades service life. In the 1970s-1980s, the stress-reducing Troposkien shape was important for aluminumrotors, but it is not as important today. The previously mentioned aerodynamic effects from parasitic drag and from struts [2] is compensated by the increased performance of the H-rotor, as its blade equatorial portion to rotor height ratio becomes unity. A multi-megawatt H-rotor requires investigations into strong and lightweight rotor-shafts, as an extended rotor shaft is prone to vibration and fatigue, primarily due to torsional stress on the shaft. Classical flutter might be a concern for straight-bladed [pitch-regulated] turbines, while dynamic stall-induced vibrations tend to be a concern for stall-regulated turbines, [32,31]. The INFLOW concept[38] utilizes a rotor shape with straight blades utilizing power increase, caused by operating in a tilted offshore environment. Pitching and counter-rotation rotors are in this case obviously dependent on wind direction influences. As mentioned, a trade-off between aerodynamic effects gained by an optimized H-rotor (such as INFLOW concept) against structural effects and wind direction sensitivity experienced by a platform has to be investigated experimentally.

\section{Loading}

As mentioned, the DeepWind concept has a modified rotor blade shape, with a constraint defined as a limiting blade strain, allowing to park and to operate safely. Analyses of the floating system with respect to vibrations were carried out using conventional NACA airfoils. A re-analysis has to be made with tailored DUWind airfoils, investigating on the risk of potential rotor blade instabilities.

For the INFLOW concept, the load and power sensibility with direction changes of wind, wave and ocean current has to be investigated and measured. This would also apply for wind shear and wind veer.

\section{CONCLUSION / DISCUSSION}

This paper presents a comprehensive review of the state-of-the-art in important aspects of torque generation and control of floating vertical-axis wind turbines. The paper summarizes what has been done from early research in the 1970s to present day. In the following, we provide a succinct summary of the main concluding points of the paper.

Important fundamental criteria for a well operating straight or curved bladed VAWT should be attained from lessons learned of addressing risk factors in the DeepWind VAWT project:

1. Structural Resonance of the elastic modes of the rotor can cause destructive vibrations if they are coincident with the per rev excitations of the aerodynamic loads. All these resonances must be avoided. The best (but 
perhaps overly expensive) solution is to put all the elastic modes above the first three harmonics of the loading in the operating range

2. Instability: Flutter (aeroelastic instability) and whirl (divergence instability) must be predicted and avoided. These instabilities are independent of wind excitation (and self-excited) and will depend only on operating speed.

3. Turbine performance depends on the stall regulation of power. VAWTs are exposed to dynamic stall, for which triggering also influenced by whether the airfoil has clean or soiled surface. Loads are also highly affected by the nature of the dynamic stall.

FVAWTs encounter excitation from the sea, and impacts from the floating support structure on modes of vibration have to be investigated. A careful analysis of the trade-off between efficiency and loads for COE has to be made on the H-type and the curved bladed VAWT. In comparison with DeepWind, INFLOW is a demonstration of technologies and trying to learn the lessons from the ongoing project. A number of important design changes of the H-design have been undertaken in the project:

- The rotor blades design intended to be used in the INFLOW prototype project VertiWind turned using blades with straight sections and twisted helically around the central axis, into using a 3-bladed rotor design with straight blades.

- Classical flutter might be a concern for straight-bladed (pitch-regulated) turbines, while dynamic stall-induced vibrations tend to be a concern for stall-regulated turbines.

- The initial design of a semi-submerged tri-floater type of floater with one turbine per floater as superstructure changed towards a design with doubling the electrical output by two counter-rotating turbines per floater allowing at the same time large tilt excursions during operation. However, the COE added value from aerodynamics, loadings and particular design has to be elaborated and verified experimentally.

The projects addressed show that the VAWT technology is in a technological position to analyze and to realize findings and R\&D solutions known from existing wind turbine - and aircraft industry, to provide more efficient and less costly concepts.

\section{ACKNOWLEDGMENTS}

This work, part of the result of Work Package 5 of the INFLOW project was supported by the European Union's Seventh Programme for research, technological development and demonstration under grant agreement No 296043 and the DeepWind project for funding under grant agreement No. 256769. Sandia National Laboratories gratefully acknowledges support from the US Department of Energy(DOE) Wind Energy Technologies Office.

\section{REFERENCES}

1. Aagaard Madsen, H. "Forskning i aeroelasticitet - EFP-98. Danmark". Risoe-R-1129[DA]], (1999)

2. Aagaard Madsen H., Schmidt Paulsen U. and Vita L."Analysis of VAWT aerodynamics and design using the Actuator Cylinder flow model" Journal of Physics: Conference Series 555 (2014) 012065 doi:10.1088/1742-6596/555/1/012065

3. Apelfröjd S., Eriksson S., and Bernhoff H."A Review of Research on Large Scale Modern Vertical AxisWind Turbines at Uppsala University" Energies, 9, 570; doi:10.3390/en9070570(2016)

4. Ashwill T. D., and Leonard T.M.”Developments in blade shape design for a Darrieus vertical axis wind turbine". SAND86-1085, Sandia National Laboratories, Albuquerque, USA, (1986.)

5. Bak C."Forskning i Aeroelasticitet, EFP-2002" RISØ-R-1434 [DA], (2002)

6. Bak C., Madsen H.A, Fuglsang P., and Rasmussen F."Observations and Hypothesis of Double Stall", in Wind Energy, 2, 195-210 (1999).

7. Bak C., Gaunaa M., and Antoniou I."Performance of the Risø-B1 Airfoil Family for Wind Turbines", in Wind energy. Proceedings of the Euromech colloquium. ed. / J. Peinke; P. Schaumann; S. Barth. Berlin: Springer, 2006. p. 231-234.

8. Bak C., Andersen P.B., Madsen H.A., Gaunaa M., Fuglsang P., and Bove S."Design and Verification of Airfoils Resistant to Surface Contamination and Turbulence Intensity", in AIAA 2008-7050, 26th AIAA Applied Aerodynamics Conference, 18 - 21 August 2008, Honolulu, Hawaii 
9. Bak C., Fuglsang P., Gaunaa M., and Antoniou I.” Design and Verification of the Risø-P Airfoil Family for Wind Turbines", in The science of making torque from wind - Delft [NL], 19-21 Apr, ISBN 90-76468-10-9, (2004)

10. Batisti L., Benini E., Brighenti A., Racitti Castelli M., DellAnna S., Dossena V., Persico, G., Schmidt Paulsen U. and Friis Pedersen T."Wind tunnel testing of the DeepWind demonstrator in design and tilted operating conditions", in Energy, 111, 484-497(2016).

11. Bedon G., Antonini E.G.A., De Betta S., Raciti Castelli M. and Benini E.'Evaluation of the different aerodynamic databases for vertical axis wind turbine simulations". In Renew. Sustain. Energy 40 386-399 (2014).

12. Bayly D., and Kentfield J. "A vertical axis cyclogiro type wind-turbine with freely-hinged blades",in Proceedings of the Intersociety Energy Conversion Conference, 2, 2053, (1981)

13. Beri H., and Yao Y.:"Effect of Camber Airfoil on Self Starting of Vertical Axis Wind Turbine", in Environ Sci Technol, 4 [3], 302-312, (2011)

14. Beri H., and Yao Y. "Numerical simulation of Unsteady Flow to Show Self-starting of Vertical Axis Wind Turbine using Fluent", in Applied Sciences, 11 [6], 962-970, (2011).

15. Borg M., and Collu M. "A Comparison on the Dynamics of a Floating Vertical Axis Wind Turbine on Three Different Floating Support Structures", in Energy Procedia, 53, 268-279, (2014)

16. Borg, M., Shires, A., and Collu, M. "Offshore Floating Vertical Axis Wind Turbines, Dynamics Modelling State of the Art. Part I: Aerodynamics", in Renew. Sustain. Energy 39, 1214-1225, (2014)

17. Cahay M., Luquiau E., Smadja C., and Silvert F. "Use of a Vertical Wind Turbine in an Offshore Floating Wind Farm", in Offshore Technol Conf, Houston, TX, USA, OTC-21705-MS, doi.org/10.4043/21705$\operatorname{MS}(2011)$.

18. Castelein D., Ragni D., Tescione G., Simão Ferreira C. J. and Gaunaa M. "Creating a benchmark of Vertical Axis Wind Turbines in Dynamic Stall for validating numerical models", Master of Science Thesis, TUDelft, AIAA 2015-0723, (2015).

19. Cheng Z. "Dynamic Modelling and Analysis of Three Floating Wind Turbine Concepts with Vertical Axis Rotor". In Proceedings of the Twenty-fifth (2015) International Ocean and Polar Engineering Conference. ISBN 978-1-880653-89-0; ISSN 1098-6189(2015)

20. "DeepWind" Project, (Accessed 25.02.2016) Available from $h \mathrm{ttp}: / / w w w . d e e p w i n d . e u$

21. Dunne R. , Hsieh-Chen T. , Colonius T. and McKeon B. J. "Leading Edge Vortex Development on Pitching and Surging Airfoils: A Study of Vertical Axis Wind Turbines 2016". In Proceedings of the 5th International Conference on Jets, Wakes and Separated Flows (ICJWSF2015), 185 581-587. DOI 10.1007/978-3-31930602-5_71. ISBN 978-3-319-30600-1

22. Dyachuk E.,and Goude A. "Simulating Dynamic Stall Effects for Vertical Axis Wind Turbines Applying a Double Multiple Streamtube Model". In Energies 8, 1353-1372; doi:10.3390/en8021353 (2015)

23. Eriksson S., and Bernhoff H. and Leijon M. "Evaluation of different turbine concepts for wind power". In ScienceDirect, 12 (2008)1419-1434. doi:10.1016/j.rser.2006.05.017

24. Ertem S., and Simão Ferreira C., Gaunaa M., and Madsen H. Aa. "Aerodynamic Optimization of Vertical Axis Wind Turbine with Trailing Edge Flaps". In Proceedings of the 34th Wind Energy Symposium, AIAA SciTech, (AIAA 2016-1735),(2016)

25. Fowler M., Bull D., and Goupee A. "A Comparison of Platform Options for Deep-water Floating Offshore Vertical Axis Wind Turbines: An Initial Study", Sandia National Laboratories Technical Report, SAND2014-16800, (2014).

26. Fuglsang P. , and Bak C. "Development of the Risø Wind Turbine Airfoils", Wind Energy 20047 145-162 (DOI: 10.1002/we.117)

27. Galinos C., Larsen T.J., Madsen H.Aa., Paulsen U.S: "Vertical Axis Wind Turbine Design Load Cases Investigation and Comparison with Horizontal Axis Wind Turbine", in Energy Procedia 2016, 94 319-328. doi.org/10.1016/j.egypro.2016.09.190 (2016)

28. Grylls W., Dale B., and Sarr P. "A Theoretical and experimental investigation into the variable pitch vertical axis wind turbine", in 2nd International Symposium on Wind Energy Systems, 2, E-9, (1978)

29. Griffith D.T., Paquette J., Barone M, Goupee A, Fowler M, Bull D. and Owens B. "A study of rotor and platform design trade-offs for large-scale floating vertical axis wind turbines", Science of making torque from wind conference, Munich, Germany,(2016). 
30. Griffith, D.T., Barone, M., Paquette, J., Owens, B., Bull, D., Simao-Ferriera, C., Goupee, A., and Fowler, M. "Design Studies for Deep-Water Floating Offshore Vertical Axis Wind Turbines", Sandia National Laboratories Technical Report, SAND2018-7002, doi:10.2172/1459118.(2018)

31. Hansen M. H. “Aeroelastic Instability Problems for Wind Turbines”, Wind Energy 10 551-577, (2007).

32. Hansen M. H. "Stall induced vibrations of a blade section in deep-stall", Research in Aeroelasticity EFP2007-II, Risø-R-1698(EN), (2007).

33. Heinz J. C., Sørensen N. N., Zahle F. and Skrzypiński W. "Vortex-induced vibrations on a modern wind turbine blade", Wind Energy 2016, doi: 10.1002/we.1967.

34. Henderson A. R., and Witcher D "Floating Offshore Wind Energy - A Review of the Current Status and an Assessment of the Prospects", Wind Engineering 34 [1], 01-16, (2010).

35. Hoerner S. F. “Fluid-Dynamic Drag”. Hoerner Fluid Dynamics: Brick Town, (1975).

36. Hoerner S. F., and Borst H.V. "Fluid dynamic Lift" Hoerner fluid Dynamics: Brick Town,(1969).

37. Howell R., Qin N., Edwards J., and Durrani, N. "Wind tunnel and numerical study of a small vertical axis wind turbine". Renewable Energy 35 412-422, (2010).

38. INFLOW, European FP7 project for demonstration (Accessed 25-02-2016) Available from: http://www.inflow-fp7.eu

39. Jain P. and Abhishek A. "Performance prediction and fundamental understanding of small scale vertical axis wind turbine with variable amplitude blade pitching". Renewable Energy, 2016 . 97(C) 97-113(2016).

40. Kelly J. A., and Hayter N-L. F. "Lift and pitching moment at low speeds of the NACA 64A010 airfoil section equipped with various combinations of a leading-edge slat, leading-edge flap, split flap, and double-slotted flap", NACA TN3007, National Advisory Committee for Aeronautics, (1953).

41. Kentfield J. "A Hybrid Cyclogiro-Darrieus Rotor Wind Turbine". Proceedings of 1st Brazilian Energy Congress, B, 4448-463, (1978).

42. Kirke B., and Lazauskas L. "Experimental verification of a mathematical model for predicting the performance of a self-acting vertical axis wind turbine", Wind Engineering, 17 [2] 58-66, (1993).

43. Klimas P.C. and Sladky J.F. "Pumped Spoiling VAWT Control", 4th ASME Wind Energy Symposium, February, (1985).

44. Klimas P.C, and Sladky J.F. "Vertical axis wind turbine power regulation through centrifugally pumped lift spoiling", INTERSOL 1985, (1985)

45. Krüger W. "Wind tunnel investigations on a changed Mustang profile with nose flap force and pressure distribution measurements", NACA technical memorandum No. 1177, (1947).

46. Kuma H., Takao M., Beppy T., Maeda T., Kamada Y., and Kamemoto K. "A straight-bladed vertical axis wind turbine with a directed guide vane - mechanism of performance improvement", Proceedings of 27th International Conference on Offshore Mechanics and Arctic Engineering, Portugal, Paper No. OMAE200857233, (2007).

47. Leishmann J. G., and Beddoes T. S. “A Semi-Empirical Model for Dynamic Stall”, Journal of the American Helicopter Society, 34 [3] 3-17[15], (1989).

48. Li Y., Tagawa K., and Liu W. "Performance effects of attachment on blade on a straight-bladed vertical axis wind turbine". Curr Appl Phys, 10, S335-S338, (2010).

49. Merz K.O. and Svendsen H.G. "A control algorithm for the deepwind floating vertical-axis wind turbine". Journal of Renewable and Sustainable Energy 5, 063136 [2013]; doi: 10.1063/1.4854675

50. Meyer R. E. "Stability Analysis of Multi-Megawatt Darrieus- Type Floating Vertical Axis Wind Turbines". Thesis DTU Wind Energy-M-0099, (2016)

51. Nobile R., Vahdati, M., Barlow J., and Mewburn-Crook A. "Dynamic stall for a Vertical Axis Wind Turbine in a two-dimensional study", World Renewable Energy Congress, Sweden, (2011).

52. Oler J. W., Strickland J. H., Im B. J., and Graham G.H. "Dynamic stall regulation of the Darrieus turbine", SAND83-7029, Sandia National Laboratories, Albuquerque, (1983).

53. Owens B. C., and Griffith D. T. "Aeroelastic stability investigations for large-scale vertical axis wind turbines", J. Phys. Conf. Ser. 524 [1], 12092, (2014).

54. Owens B.C., Griffith D.T., and Hurtado J.E. "Modal Dynamics and Stability of Large Multi-megawatt Deepwater Offshore Vertical-axis Wind Turbines: Initial Support Structure and Rotor Design Impact Studies", 32nd ASME Wind Energy Symposium, National Harbor, MD, USA, January 2014,(2014).

55. Paraschivoiu I. "Wind turbine design with emphasis on Darrieus concept", Quebec: Presses Internationales Polytechnique, (2002). 
56. Pawsey N.C.K. "Development and evaluation of passive variable-pitch vertical axis wind turbines", PhD Thesis, The University of New South Wales, (2003).

57. Paulsen U.S., Madsen H.A., Kragh K. A.,Nielsen P.H., Baran I., Hattel J., Ritchie E., Leban, K., Svendsen H. and Berthelsen P.A. "DeepWind-from Idea to 5 MW Concept". Energy Procedia 53 23-33. ISSN 18766102,(2014)

58. Paulsen U. S., Borg M., Madsen H. Aa., Pedersen T. F., Hattel, J., Ritchie, E., Ferreira, C. S., Svendsen, H., Berthelsen, P. A., and Smadja, C. "Outcomes of the DeepWind conceptual design", Energy Procedia, 80 329-341 (2015).

59. Pirrung et al.. "Dynstall report"., (2016).To be published

60. Ragni D., Simão Ferreira C. and Correale C. "Experimental investigation of an optimized airfoil for verticalaxis wind turbines" Wind Energy 18 1629-1643, (2014). DOI: 10.1002/we.1780 2014

61. Riegels FW. "Aerofoil sections". Butterworth (1961)

62. Ritchie E., Leban, K., and Paulsen, U.S. "Electrical aspects of the DeepWind $5 \mathrm{MW}$ floating Vertical Axis Wind Turbine", Sixth International Symposium on Energy Challenges and Mechanics, Inverness, (2016).

63. Ritchie E., Leban K., Trintis I., Nica F. V. T., Boian D., Biris C., Burlacu P. D., Shivachev S., and Paulsen U. S. "On the Design and Performance of a Power Electronics Converter for the DeepWind project", EUROMECH Colloquium on Scientific and Technological Challenges in Offshore Vertical Axis Wind Turbines Delft, (2016), submitted to AIP and under review

64. Sandia VAWT project "Innovative offshore vertical-axis wind turbine rotors" [Accessed 3.03.2016] Available from: http://energy.sandia.gov/energy/renewable-energy/wind-power/offshore-wind/innovativeoffshore-vertical-axis-wind-turbine-rotors/

65. Scheurich F., and Brown R. "Vertical-axis wind turbines in oblique flow: sensitivity to rotor geometry". EWEA Annual event (formerly known as EWEC) (2011).

66. Sicard C. "Fluid current turbine". United States Patent 4.048.947, (1977).

67. Simão Ferreira C., and Geurts B. "Aerofoil optimization for vertical axis wind turbines", Wind Energy 18 1371-1385, (2015)

68. Skrzypiński W., and Gaunaa M. "Wind turbine blade vibration at standstill conditions - the effect of imposing lag on the aerodynamic response of an elastically mounted airfoil", Wind Energy 2014, doi: 10.1002/we.1712.

69. Skrzypiński W., Gaunaa M., Sørensen N., Zahle F., and Heinz J. "Vortex-induced vibrations of a DU96W-180 airfoil at $90^{\circ}$ angle of attack" Wind Energy [2013] DOI: 10.1002/we.1647

70. Sutherland H. J., Berg D. E., and Ashwill T. D. "A retrospective of VAWT technology", SAND2012-0304, Sandia National Laboratories, Albuquerque, USA, (2012).

71. Takao M., Maeda T., Kamada Y., Oki M., and Kuma H. "A straight-bladed vertical axis wind turbine with a directed guide vane row", Proceedings of the 5th Joint ASME/JSME Fluids Engineering Conference, San Diego, USA, Paper No. FEDSM2007-37422, 2007.

72. Takao M., Takita H., and Saito Y. "Experimental study of a straight-bladed vertical axis wind turbine with a directed vane row", Proceedings of the 28th International Conference on Ocean, Offshore and Arctic Engineering, Honolulu, (2009).

73. Templin R. J., and South P."Canadian wind energy program, Proceedings of the vertical-axis wind turbine technology workshop Albuquerque, New Mexico, May 18-20", SAND 76-5586,(1976).

74. Theodorsen, T. "General theory of aerodynamic instability and the mechanism of flutter2, NACA report 496, (1935).

75. Thirstrup Petersen J., Thomsen K., and Aagaard Madsen H. "Stall strips can control edgewise vibrations", AED-RB-6[EN], (1998).

76. Timmer W. A., and van Rooij R. P. J. O. M. "Summary of the Delft University Wind Turbine Dedicated Airfoils", Journal of Solar Energy Engineering 125[4], (2003).

77. Tjiu W., Marnoto, T., Mat S., Ruslan M. H., and Sopian K. "Darrieus vertical axis wind turbine for power generation I: Assessment of Darrieus VAWT configurations", Renew. Energ 75 50-67, (2015).

78. Verelst D. R. S., Aagaard Madsen H., Kragh K. A. and Belloni F. "Detailed Load Analysis of the baseline 5MW DeepWind Concept", DTU Wind Energy, E-0057, (2014).

79. Walters R. E., Fanucci J. B., Hill, P. W., and Migliore P. G. "Vertical axis wind turbine development", SAND 5665084, (1979). 
80. Wang K., Moan T. and Hansen M.O.L. "A method for modeling of floating vertical axis wind turbine". In Proceedings of the ASME 2013 32nd International Conference on Ocean, Offshore and Arctic Engineering, OMAE2013-10289.

81. Yusuf Billah K., and Scanlan R. H. "Resonance, Tacoma Narrow bridge failure, and undergraduate physics textbooks". Am. J. Phys. 59 2, (1991). 